\title{
Assessment of Pulmonary Fibrogenic Potential of Multiwalled Carbon Nanotubes in Human Lung Cells
}

\author{
Anurag Mishra, ${ }^{1,2}$ Yon Rojanasakul, ${ }^{2}$ Bean T. Chen, ${ }^{1}$ Vincent Castranova, ${ }^{1}$ \\ Robert R. Mercer, ${ }^{1}$ and Liying Wang ${ }^{1}$ \\ ${ }^{1}$ Pathology and Physiology Research Branch, Health Effects Laboratory Division, National Institute for Occupational Safety and Health, \\ Morgantown, WV 26505, USA \\ ${ }^{2}$ Department of Pharmaceutical Sciences, West Virginia University, Morgantown, WV 26506, USA
}

Correspondence should be addressed to Anurag Mishra, amishra@hsc.wvu.edu

Received 13 January 2012; Revised 25 March 2012; Accepted 25 March 2012

Academic Editor: Ivo Iavicoli

Copyright () 2012 Anurag Mishra et al. This is an open access article distributed under the Creative Commons Attribution License, which permits unrestricted use, distribution, and reproduction in any medium, provided the original work is properly cited.

\begin{abstract}
Multiwalled carbon nanotubes have been shown to possess unusual fibrogenic activity in vivo and are currently the focus of intense toxicological investigations. This study further determines the fibrogenic potential of well-dispersed MWCNT in human lung cell culture models and to develop a novel platform for understanding the cellular mechanisms of MWCNT-induced lung fibrosis. Survanta, a natural lung surfactant, showed effectiveness in dispersing agglomerates of MWCNT to fine structures similar in size to aerosolized one. At relevant low doses $\left(0.002-0.2 \mu \mathrm{g} / \mathrm{cm}^{2}\right)$, MWCNT exhibited a dose-dependent bio-effect on the human lung epithelial cells which is more pronounced in dispersed-MWCNT compared to non-dispersed form. Significantly elevated levels of fibrogenic mediators, such as transforming growth factor- $\beta 1$ and matrix metalloprotienases- 9 were observed in the dispersed-MWCNT treated lung epithelial cells. Based on previous in vivo studies showing that dispersed-MWCNT penetrated the interstitium and caused rapid interstitial fibrosis, we evaluated the potential direct interaction between lung fibroblasts and MWCNT. Direct stimulation of human lung fibroblast cell proliferation, collagen expression and fibroblast growth factor- 2 were observed which suggests novel mechanisms of MWCNT-induced lung fibrosis. Our results indicate that the dispersion status of MWCNT determines their fibrogenic activity which is consistent with in vivo findings.
\end{abstract}

\section{Introduction}

Graphene-based multilayered nanofibers (less than $100 \mathrm{~nm}$ in diameter), widely known as multiwalled carbon nanotubes (MWCNT), have wide commercial applications due to their unique properties such as high tensile strength and electrical conductivity. Their nanosized structure and low density make them a potential airborne health hazard [13]. However, the potential toxicity of fibrous MWCNT, especially the adverse effects to human, is relatively unknown. Research on this issue is urgently needed due to their rapidly increasing use. Recent in vivo studies have shown that dispersed MWCNT induce interstitial lung fibrosis (only 14 weeks post exposure) without causing persistent lung inflammation $[4,5]$. Previous studies by our group have shown that dispersion of CNT is a key factor determining its cellular interactions and bioactivities but the underlying mechanisms of this unusual fibrosis are unknown [6-8].
We hypothesize that MWCNT induce fibrotic response by directly stimulating lung fibroblasts to produce collagen while stimulating lung epithelial cells to secrete profibrogenic factors that promote the fibrotic process.

Interstitial lung fibrosis is considered an aberrant woundhealing response characterized by excessive extracellular matrix (ECM) protein deposition (e.g., collagen) in the interstitial space [9]. Environmental and occupational exposure to inhaled particulate matters is a leading cause of pulmonary fibrosis resulting from dysregulated cytokine production and repair mechanisms [10]. Transforming growth factor$\beta 1$ (TGF- $\beta 1$ ) and matrix metalloproteinases (MMPs) are key pulmonary mediators released by wounded or stressed lung cells and their role in normal wound healing and pathologic fibrosis is well established [10-12]. TGF- $\beta 1$ is known to induce lung fibrosis [11]. Members of MMP such as MMP2, 4, 7, and 9 are known mediators of fibrosis where they 
promote the recruitment of inflammatory and immune cells to the site of injury [12-15], MMP-9 specifically breakdowns extracellular matrix proteins. Under normal condition, these mediators are expressed in low levels but are elevated during cell injury and inflammation [16]. Although other fibrotic mediators are involved in the fibrotic process, TGF- $\beta 1$ and MMP-9 are major and reliable indicators of fibrotic responses and were focused on in this study for potential biomarkers of nanoparticle-induced lung fibrosis.

Recent in vivo data have shown that well-dispersed carbon nanotubes (CNTs) exhibit a more distal lung deposition pattern and greater penetration into the alveolar interstitium, terminal bronchioles, and proximal alveolar space as compared to their agglomerate form which deposits mainly in the airspaces [6]. Deeper lung deposition of dispersed CNT may directly induce unusual interstitial fibrosis in vivo but direct evidence and detailed cellular mechanism are still lacking. Therefore, lung epithelial cell and fibroblast cell were chosen for this study.

The main objective of this study was to develop in vitro models for fibrogenicity testing of CNT which may be used to investigate the mechanisms of lung fibrosis induced by CNT and other nanomaterials. The models could allow one to measure the induction of collagen, TGF- $\beta 1$, or MMP by MWCNT-treated human lung cells which could serve as potential biomarkers for MWCNT-induced fibrosis. Therefore, this study could have a predictive value in developing simple and inexpensive in vitro assays for fibrogenesis. There is an urgent need for this rapid and reliable in vitro method to evaluate and predict the potential toxicity and fibrogenicity of nanomaterials since their applications and incorporation into commercial products is rapidly growing without a full understanding of their possible health consequences upon exposure.

\section{Materials and Methods}

2.1. MWCNT Source and Preparation. MWCNT used in this study were provided by Mitsui \& Company (MWNT7, lot no. 05072001K28) containing 0.41\% metal impurity. MWCNT was suspended in phosphate buffer saline (PBS) at $0.1 \mathrm{mg} / \mathrm{mL}$ as nondispersed-MWCNT (ND-MWCNT). The natural lung surfactant Survanta (Abbott Laboratories, Columbus, $\mathrm{OH}$ ) was used as a dispersion agent since it exhibited no apparent cytotoxicity and had no masking effect on the bioactivity of CNT [17]. Survanta-dispersedMWCNT (SD-MWCNT) were prepared by addition of $150 \mu \mathrm{g} / \mathrm{mL}$ of Survanta. Before exposure, ND-MWCNT and SD-MWCNT were lightly sonicated (Sonic Vibra Cell Sonicator, Sonic \& Material Inc., Newtown, CT, USA) with the power, frequency, and amplitude settings of $130 \mathrm{~W}$, $20 \mathrm{kHz}$, and $60 \%$ for $10 \mathrm{sec}$. As negative control particle, dispersed ultrafine carbon black (UFCB), which does not show any fibrogenic or cytotoxic bioactivity in vivo, was used [18].

2.2. MWCNT Characterization and Size Measurements. Field emission scanning electron microscopy (FESEM, model S4800; Hitachi, Tokyo, Japan) was used for size distribution analysis. ND- and SD-MWCNT were filtered onto a polycarbonate filter (VCTP02500 isopore membrane; Millipore, Billerica, MA). After washing with purified water and drying, the filter was cut into equal sections, mounted onto aluminum stubs with double-stick carbon tape and sputtercoated with gold/palladium. The deposited particles were viewed under a FESEM at 400X and 30,000X magnifications. Mean length and width size distributions (log normal) of the particles in each sample were determined by analysis of a minimum of 300 particle structures (dispersed or nondispersed form) (N). Count median length (CML) and count median width (CMW) were determined for each group.

2.3. Cell Culture and Proliferation Assays. Human lung epithelial BEAS-2B cells were obtained from American Type Culture Collection (ATCC, Manassas, VA) and were grown in Dulbecco's Modified Eagle Medium containing 5\% fetal bovine serum, 1\% Penicillin/streptomycin and 1\% LGlutamine (Sigma, St. Louis, MO). BEAS-2B cells were derived from normal human bronchial epithelium and were immortalized with a replication-defective SV40/adenovirus 12 hybrid. Human alveolar basal epithelial A549 cells (ATCC, Manassas, VA) were grown in F-12 K Medium containing 5\% fetal bovine serum, 1\% Penicillin/streptomycin and 1\% LGlutamine (Sigma, St. Louis, MO). FibroblastCRL-1490 cells (ATCC, Manassas, VA) were derived from normal human lung fibroblasts and were cultured in Minimum Essential Medium (MEM) containing 5\% fetal bovine serum, 1\% Penicillin/streptomycin and 1\% L-Glutamine (Sigma, St. Louis, MO). For cell viability assay, cells were seeded in 24 well plates $\left(2 \times 10^{4}\right.$ cells/well $)$ and treated with ND-MWCNT or SD-MWCNT. Cell viability was measured after $48 \mathrm{~h}$ by trypan blue assay using Countess automatic cell counter (Invitrogen, Carlsbad, CA). Cell proliferation was analyzed by using the 4-[3-(4-iodophenyl)-2-(4-nitrophenyl)-2H-5tetrazolio]-1,3-benzene disulfonate (WST-1) assay (Roche Diagnostic, Mannheim, Germany) according to the manufacturer's instructions. Briefly, cells $\left(3 \times 10^{3}\right.$ cells/well $)$ were cultured in 96-well plates and exposed to ND- or SDMWCNT. At $48 \mathrm{~h}$ after -exposure, cells were washed with PBS and $100 \mu \mathrm{L}$ of the WST-1 dye were added to each well and allowed to incubate for $4 \mathrm{~h}$. Absorbance was then measured at $450 \mathrm{~nm}$ using a plate reader (Molecular Device Spectra max 250, Sunnyvale, CA).

2.4. Western Blot Analysis and ELISA. Cells were cultured in 6-well tissue culture plates $\left(1 \times 10^{5}\right.$ cells/well $)$ and exposed to SD-MWCNT and various controls. At $48 \mathrm{~h}$ after exposure, conditioned media were collected for ELISA. Cells were washed twice with ice cold PBS. After a 10 min incubation with lysis buffer (Cell Signaling Technology, Danvers, MA) containing $1 \mathrm{mM}$ phenylmethylsulfonyl fluoride (PMSF) and a complete protease inhibitor cocktail (Roche, Mannheim, Germany), cells were scraped and cell lysates were collected for analysis of total protein content using bicinchoninic assay (Pierce Biotechnology, Rockford, IL). Equal amounts of total protein in each sample were separated by sodium dodecyl sulfate-polyacrylamide gel electrophoresis (SDS-PAGE) and 
the resolved protein was transferred to a nitrocellulose membrane. The membrane was blocked for $1 \mathrm{~h}$ in TBST buffer (25 mM Tris- $\mathrm{HCl}$, pH 7.4, $125 \mathrm{mM} \mathrm{NaCl,} \mathrm{0.05 \%} \mathrm{Tween} \mathrm{20)}$ containing 5\% nonfat dry milk and incubated overnight at $4^{\circ} \mathrm{C}$ with a primary antibody specific to TGF- $\beta 1$ (Cell Signaling Technology, Danvers, MA), MMP-9 (R\&D Systems, Minneapolis, MN), fibroblast growth factor (FGF)-2 (Cell Signaling, Danvers, MA), or collagen I (Fitzgerald, Concord, MA). After primary antibody incubation, the membrane was washed and incubated with horseradish peroxidaseconjugated secondary antibody for $1 \mathrm{~h}$ at room temperature. The immune complexes were then detected by chemiluminescence (Supersignal West Pico, Pierce, Rockford, IL) and quantified by densitometry using Adobe Photoshop image analysis software (Adobe Software, San Jose, CA).

For analysis of secreted TGF- $\beta 1$ and MMP- 9 , conditioned media were collected and analyzed for the secreted proteins using commercial ELISA kits from Invitrogen (Carlsbad, CA) and EMD Chemicals (Gibbstown, UK), respectively. Briefly, $100 \mu \mathrm{L}$ of cell culture supernatant were added to pre-antibody-coated 96-well plates for $2 \mathrm{~h}$, after which biotinylated peroxidase-conjugated secondary antibody was added and the reaction was stopped by adding an acid solution. The plate was then read for absorbance at $450 \mathrm{~nm}$ (Molecular Device Spectra max 250, Sunnyvale, CA).

2.5. Sircol Soluble Collagen Assay. Sircol red collagen assay kit (Biocolor Ltd., UK) was used to measure total soluble collagen, according to the manufacturer's protocol. Briefly, fibroblasts $\left(1 \times 10^{5}\right.$ cells/well $)$ were cultured in 6-well plates and treated with MWCNT $\left(0.02-0.06 \mu \mathrm{g} / \mathrm{cm}^{2}\right)$ for $48 \mathrm{~h}$. Cell supernatants were collected and mixed with Sircol red dye reagent for $30 \mathrm{~min}$. A $200 \mu \mathrm{L}$ aliquot of the mixed supernatant was transferred to a 96-well plate and analyzed for absorbance at $555 \mathrm{~nm}$ (Molecular Device Spectra Max 250, Sunnyvale, CA).

2.6. Statistical Analysis. ANOVA was performed to determine statistical significance between treatment and control groups using Graph Pad Prism 5.1 (GraphPad Software Inc., La Jolla, CA) at a confidence level of $P<0.05^{*}$.

\section{Results}

3.1. Characterization and Size Distribution Analysis of NDand SD-MWCNT. To reduce agglomeration, the MWCNT used in this study were dispersed in PBS containing $150 \mu \mathrm{g} / \mathrm{mL}$ of the natural lung surfactant, Survanta. This concentration is physiologically relevant to the surfactant concentration present in the lung lavage fluids and shown to have no cytotoxic effect and did not mask the surface activity of particles. FESEM analysis of Survanta-dispersed MWCNT shows that the surfactant is effective in reducing the MWCNT agglomerate size (Figure 1). Figures 1(a)-1(c) show images of ND-MWCNT at increasing magnifications, while Figures 1(d)-1(f) depict images of SD-MWCNT in similar condition. Structure sizes were much smaller in the SD-MWCNT preparation with the count median width (CMW) and count median length (CML) of $78 \mathrm{~nm}$ and
$5.1 \mu \mathrm{m}$, respectively, versus ND-MWCNT with the CMW and CML of $1.3 \mu \mathrm{m}$ and $10.4 \mu \mathrm{m}$ (Figure 2). Table 1 gives the average mean diameter and length of 300 of SD-MWCNT versus ND-MWCNT agglomerate structure measurements. The mean width of SD-MWCNT structures was about $80 \mathrm{~nm}$ which is comparable to the average diameter of aerosolized MWCNT [19]. These results indicate that Survanta substantially improves the aqueous dispersion of MWCNT at the concentration used. Furthermore, Survanta-dispersed MWCNT remains physically stable with no appreciable changes in particle size during storage at $4^{\circ} \mathrm{C}$ for months as determined by electron microscopy. SD-MWCNT appeared more dispersed and interacted more with the cells than NDMWCNT (Figure 3).

3.2. SD-MWCNT Induces More Cytotoxic Effect in Lung Epithelial Cells than ND-MWCNT. Cultured human lung epithelial BEAS-2B cells were exposed to ND- or SDMWCNT and examined for MWCNT distribution and cytotoxicity. The studies were performed to optimize the doses relevant to in vivo studies based on previously published data $[4,8]$. The doses of MWCNT used in this study $\left(0.002-0.6 \mu \mathrm{g} / \mathrm{cm}^{2}\right)$ are physiologically relevant (equivalent to dosimetry used in in vivo MWCNT exposure studies at $\mathrm{NIOSH}$ ) and derived from in vivo pulmonary exposure in mice $\left(10-80 \mu \mathrm{g} /\right.$ mouse with $500 \mathrm{~cm}^{2}$ estimated lung surface area, which correspond to $0.02-0.16 \mu \mathrm{g} / \mathrm{cm}^{2}$ ) [4-6].

To assess the effects of MWCNT on BEAS-2B cell viability and proliferation, direct cell counting and WST-1 cell proliferation assays were performed. Since CNT interfere with colorimetric dyes used in cytotoxicity assays, these separate cytotoxicity assays were performed to avoid any artificial results [20]. Figure 4(a) shows a dose-dependent effect of ND- and SD-MWCNT exposure on BEAS-2B cell viability. Survanta only as a dispersion agent background control and UFCB as negative particle control showed no effect on cell viability or proliferation. Both ND- and SDMWCNT caused a dose-dependent decrease in cell viability at the concentration of $0.06 \mu \mathrm{g} / \mathrm{cm}^{2}$ or higher compared to Survanta and UFCB $\left(0.6 \mu \mathrm{g} / \mathrm{cm}^{2}\right)$. However, the effect was significantly more pronounced in SD-MWCNT-treated cells as compared to ND-MWCNT treated cells. ND- and SD-MWCNT also showed a similar dose-dependent effect on cell proliferation as determined by WST-1 formazan dye assay [21] (Figure 4(b)). Both forms of MWCNT inhibited cell proliferation at doses $>0.2 \mu \mathrm{g} / \mathrm{cm}^{2}$ with SD-MWCNT being more potent, while Survanta alone and UFCB had no significant effect on both cell viability and proliferation under the experimental condition. A similar result was also observed in human lung adenocarcinoma A549 cells which are slightly less sensitive to MWCNT than the BEAS-2B cells (see Figures 1 and 2 in the Supplementary Material available online at doi:10.1155/2012/930931). Since dispersed MWCNT are structurally similar to the aerosolized MWCNT used during in vivo inhalation exposure, SD-MWCNTs were selected for subsequent experiments in this study.

3.3. SD-MWCNT Induces TGF- $\beta 1$ in Human Lung Epithelial Cells. BEAS2B cells were treated with SD-MWCNT and 
TABLE 1: Size distribution analysis of agglomerates of ND \& SD-MWNCT. The values in Table 1 are mean values computed by adding up a collection of numbers and dividing by their count (300 fibre particles were measured in each group).

\begin{tabular}{lcr}
\hline & Length (Mean \pm S.D.) & Width (mean \pm S.D.) \\
\hline Nondispersed MWCNT agglomerate structures & $15.2 \pm 1.0 \mu \mathrm{m}$ & $7.7 \pm 1.3 \mu \mathrm{m}$ \\
Survanta-dispersed MWCNT agglomerate structures & $4.9 \pm 0.54 \mu \mathrm{m}$ & $0.082 \pm 0.002 \mu \mathrm{m}$ \\
\hline
\end{tabular}

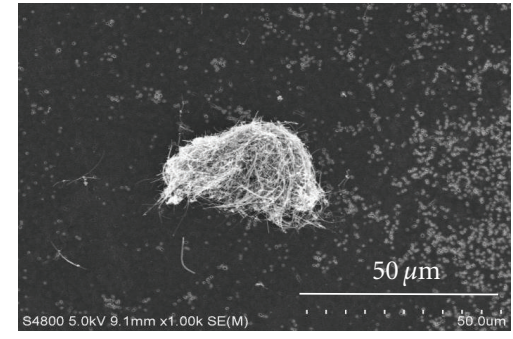

(a)

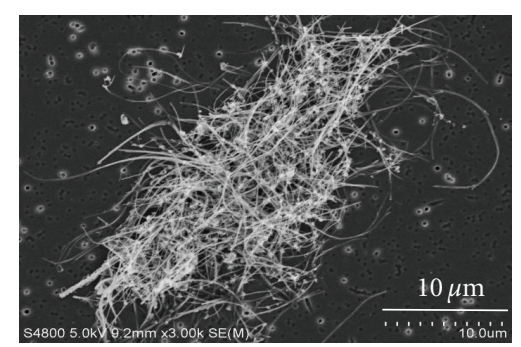

(b)

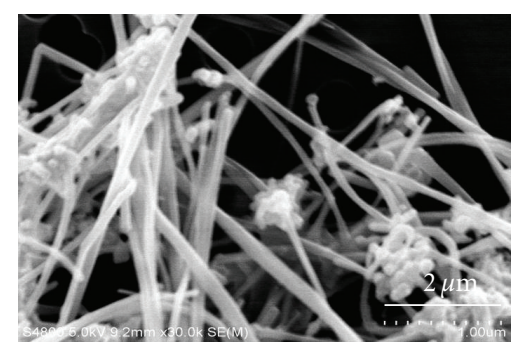

(c)

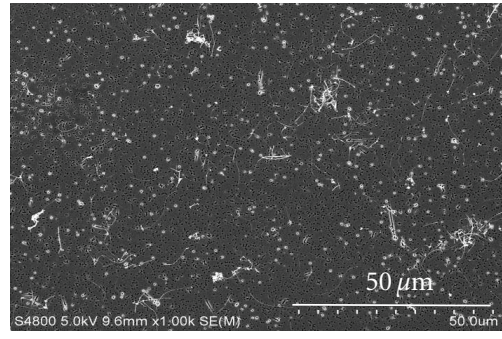

(d)

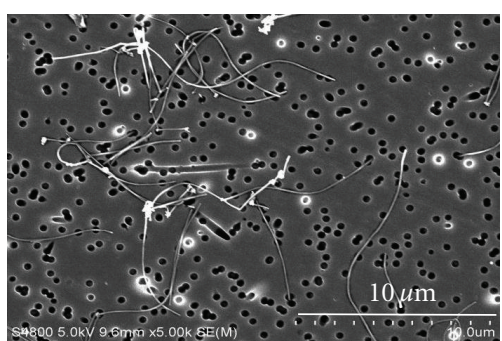

(e)

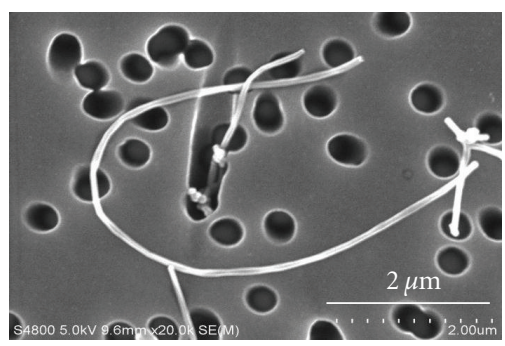

(f)

FIGURE 1: Particle characterization of nondispersed (ND) and Survanta-dispersed (SD) MWCNT. Field emission scanning electron micrograph of nondispersed ((a)-(c)) and Survanta-dispersed MWCNT ((d)-(f)) at increasing magnifications (scales show $50 \mu \mathrm{m}, 10 \mu \mathrm{m}$, and $2 \mu \mathrm{m}$ resp.). Large agglomerates of MWCNT are present in ND-MWCNT preparations (left panel) while small well-dispersed structures are present in the SD-MWCNT sample (right panel).

Survanta only control for $48 \mathrm{~h}$. TGF- $\beta 1$ expression in cells was measured by Western blot assay using cell lysates. Cell supernatants were also collected and analyzed for secreted TGF- $\beta 1$ levels by ELISA. Figure 5(a) shows that MWCNTtreatment significantly increased the cellular expression of TGF- $\beta 1$ over vehicle control (Survanta) and UFCB levels. A similar finding was observed with the secreted TGF- $\beta 1$ with elevated levels in the SD-MWCNT-treated samples as compared to nontreated and vehicle controls (Figure 5(b)).

\subsection{SD-MWCNT Induces MMP-9 in Human Lung Epithelial} Cells. MMP-9 expression was also measured in MWCNTtreated BEAS-2B cells from the same experiment of MWCNT-induced TGF- $\beta 1$ by Western blotting. Figure 6(a) shows that MWCNT were able to significantly induce MMP9 expression at the same concentration range that induces
TGF- $\beta 1$ (e.g., $0.02-0.2 \mu \mathrm{g} / \mathrm{cm}^{2}$ ). Also levels of secreted MMP9 (Figure 6(b)) were significantly higher in conditioned media from SD-MWCNT cells versus controls. SD-MWCNT upregulated the expression of MMP-9 (Figure 6), suggesting the involvement of this fibrogenic mediator in MWCNTinduced fibrosis. This study also suggests that MMP-9 and TGF- $\beta 1$ may serve as potential in vitro biomarkers for CNTinduced fibrogenesis.

3.5. Dose-Dependent Effects of SD-MWCNT on Fibroblast Cell Proliferation, Collagen Expression, and Cytotoxicity. Based on in vivo data that pulmonary exposed dispersed MWCNT can enter the lung interstitium, we addressed the potential direct interaction and stimulating effect of dispersed MWCNT on lung fibroblasts. Human lung fibroblast CRL-1490 cells were treated with various concentrations of SD-MWCNT 


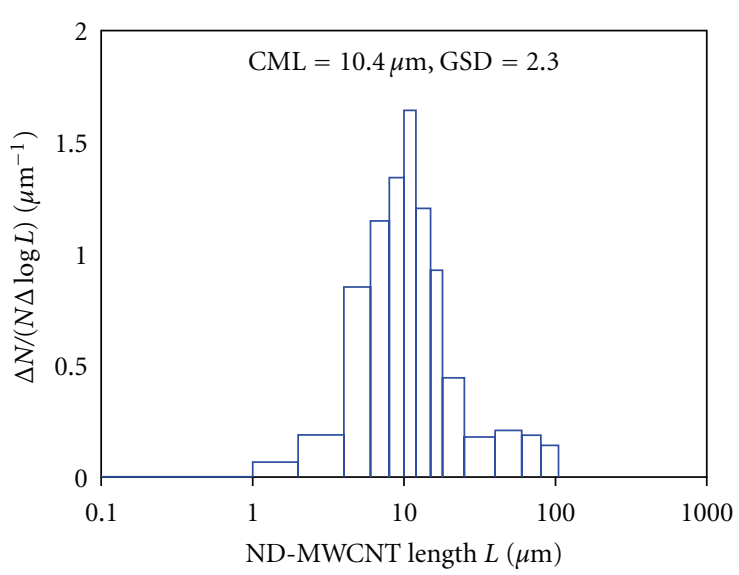

(a)

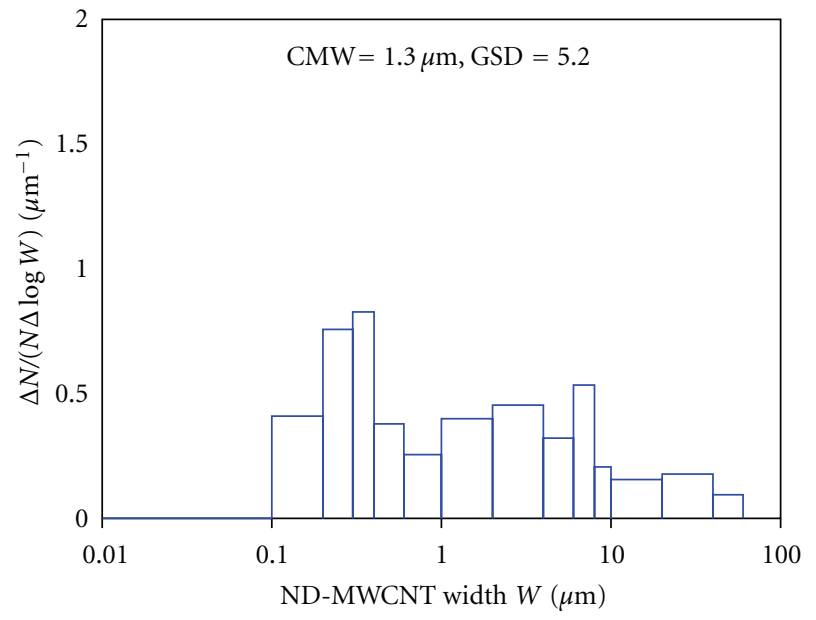

(c)

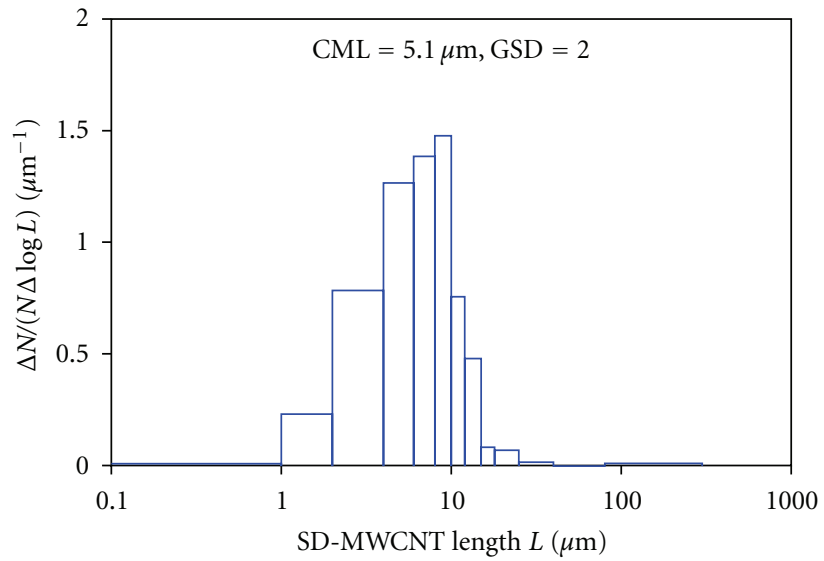

(b)

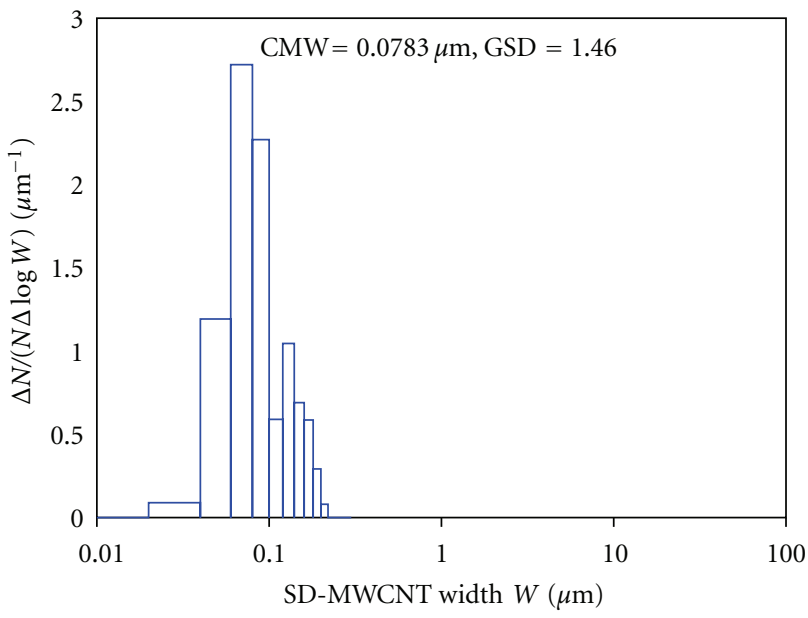

(d)

FIGURE 2: Size distribution analysis of agglomerates of nondispersed (ND) and Survanta-dispersed (SD) MWCNT. MWCNT were suspended in PBS in the absence or presence of Survanta. The values are median values of distribution. Length and width distribution (log normal) of ND-MWCNT are shown in (a) and (c), while length and width distribution (log normal) of SD-MWCNT are shown in (b) and (d). N: MWCNT particle (agglomerates) number. Total counted particles are 300 in each case. CMW: count median width; CML: count median length; GSD: geometric standard deviation.

and analyzed for cell proliferation and collagen production. Figure 7(a) shows that SD-MWCNT exhibited a dual effect on cell proliferation, that is, stimulating effect at low doses $\left(0.002-0.06 \mu \mathrm{g} / \mathrm{cm}^{2}\right)$ and inhibitory effect at high doses $\left(\geq 0.6 \mu \mathrm{g} / \mathrm{cm}^{2}\right)$. Figure $7(\mathrm{~b})$ shows that SD-MWCNT-induced collagen I expression in lung fibroblasts compared to controls as determined by Western blotting which was performed on the basis of equal protein content and the results normalized by $\beta$-actin content. Analysis of soluble collagen in the treated cell culture medium by Sircol assay (Figure 7(c)) further showed that SD-MWCNTs were able to induce collagen secretion from the treated cell, supporting the direct fibrogenic effect of SD-MWCNT on lung fibroblasts.

3.6. SD-MWCNT Induces FGF-2 Expression in CRL-1490 Cells. FGF-2 is a potent angiogenic factor and a key stimulant for fibroblast cell proliferation and TGF- $\beta 1$-mediated collagen induction [17]. To support the direct fibrogenic effect of SD-MWCNT on lung fibroblasts, we analyzed FGF-2 induction in MWCNT-treated fibroblasts. As expected, SDMWCNT induced FGF-2 expression in a dose-dependent manner (Figure 8), consistent with its direct proliferative and collagen-inducing effects (Figure 7).

\section{Discussion}

The underlying cellular mechanism of the unusual fibrogenicity of MWCNT is largely unknown due in part to the lack of well-characterized experimental models. In vivo models using animal provide valuable information of nanoparticle induced lung disorders such as fibrosis. Based on the in vivo data, we investigated the mechanisms of CNTinduced lung fibrosis in vitro which allows more detailed investigations such as dispersion status and dose effect of MWCNT, response of human cells to MWCNT, and role of individual cell type. Success of the in vitro model 


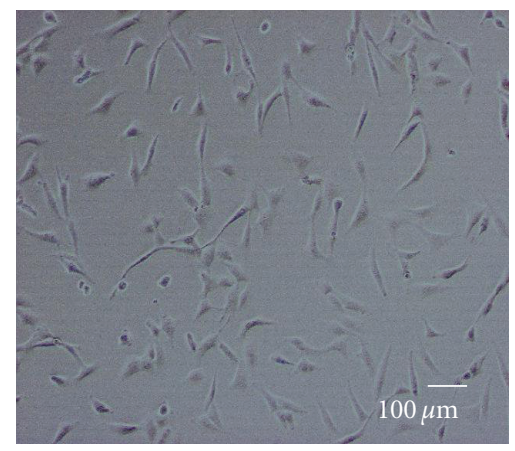

(a)

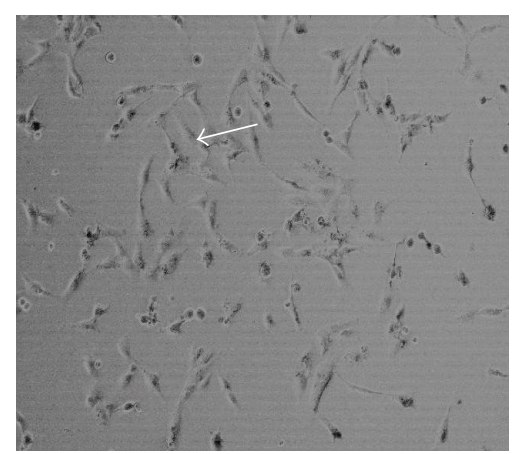

(c)

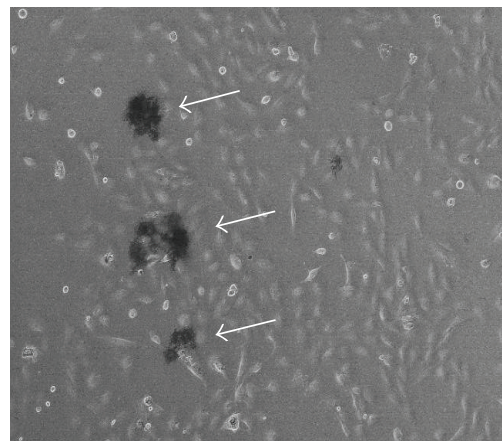

(b)

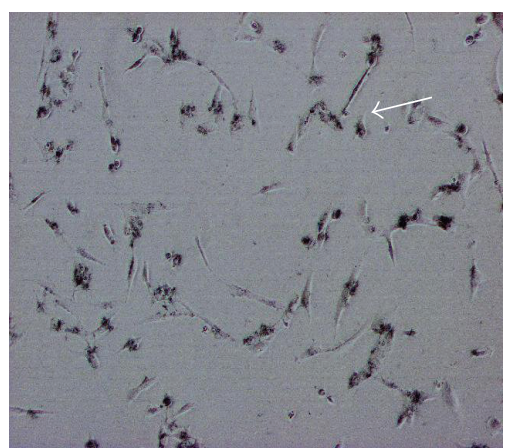

(d)

FIgURE 3: Light microscopy of nondispersed (ND) and Survanta-dispersed (SD) MWCNT-treated BEAS2B cells. BEAS-2B cells were either left untreated (a) or treated with (b) $0.2 \mu \mathrm{g} / \mathrm{cm}^{2}$ of ND-MWCNT, (c) $0.2 \mu \mathrm{g} / \mathrm{cm}^{2}$ of SD-MWCNT, or (d) $0.6 \mu \mathrm{g} / \mathrm{cm}^{2}$ of SD-MWCNT for $48 \mathrm{~h}$. Large agglomerates (white arrow) were seen with ND-MWCNT (b), whereas much smaller structures of MWCNT were observed (CD). Note the interaction of cells with MWCNT which is more apparent in SD-MWCNT-treated cells.

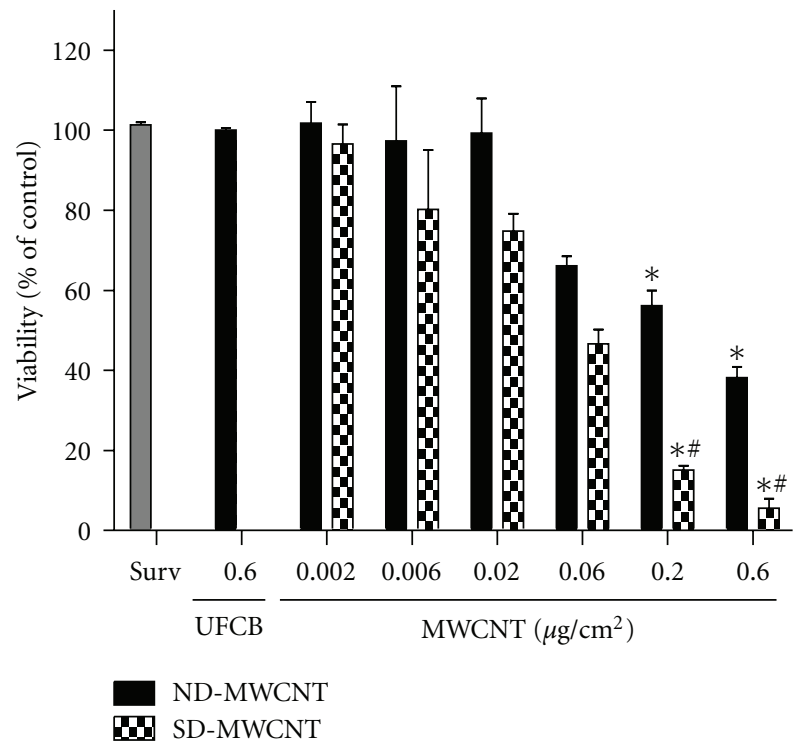

(a)

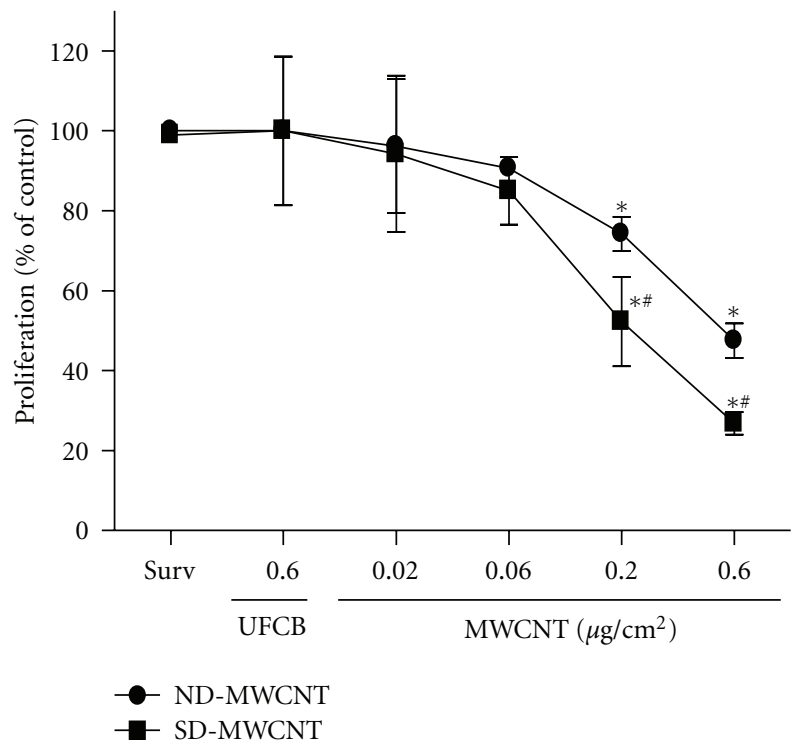

(b)

FIGURE 4: Effect of Survanta-dispersed MWCNT on cell viability and proliferation. BEAS-2B cells were exposed to $0.002-0.6 \mu \mathrm{g} / \mathrm{cm}^{2}$ of nondispersed (ND-MWCNT) or Survanta-dispersed MWCNT (SD-MWCNT) for $48 \mathrm{~h}$. Cell viability and proliferation were determined by (a) trypan blue exclusion assay, and (b) WST-1 cell proliferation assay. Plots are mean \pm S.D. from 4 independent experiments. ${ }^{*} P<0.05$ versus nontreated survanta control; ${ }^{\#} P<0.05$ versus ND-MWCNT treatment. 


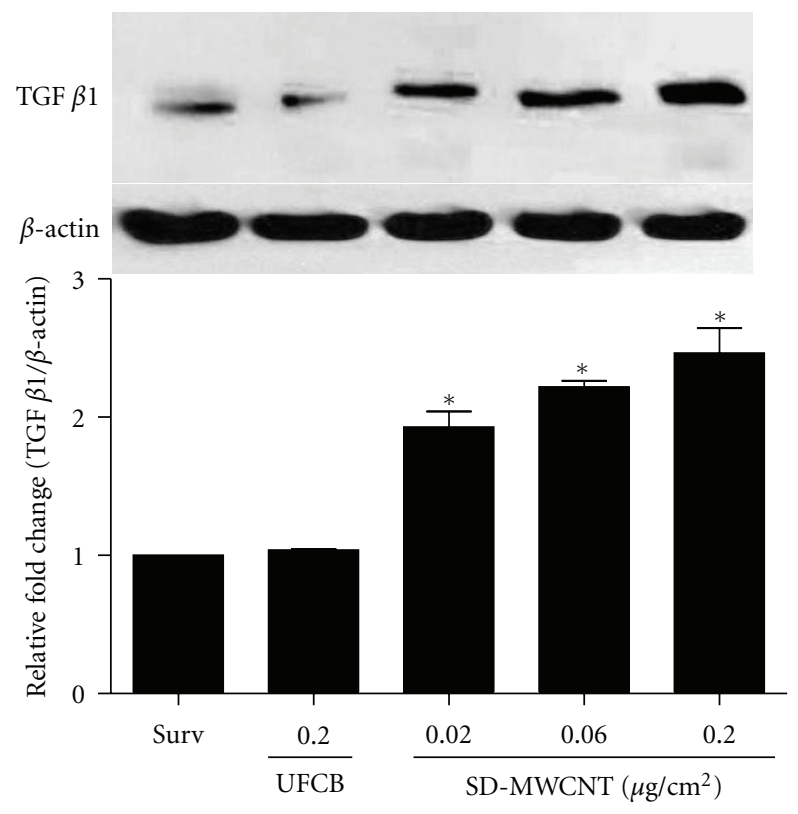

(a)

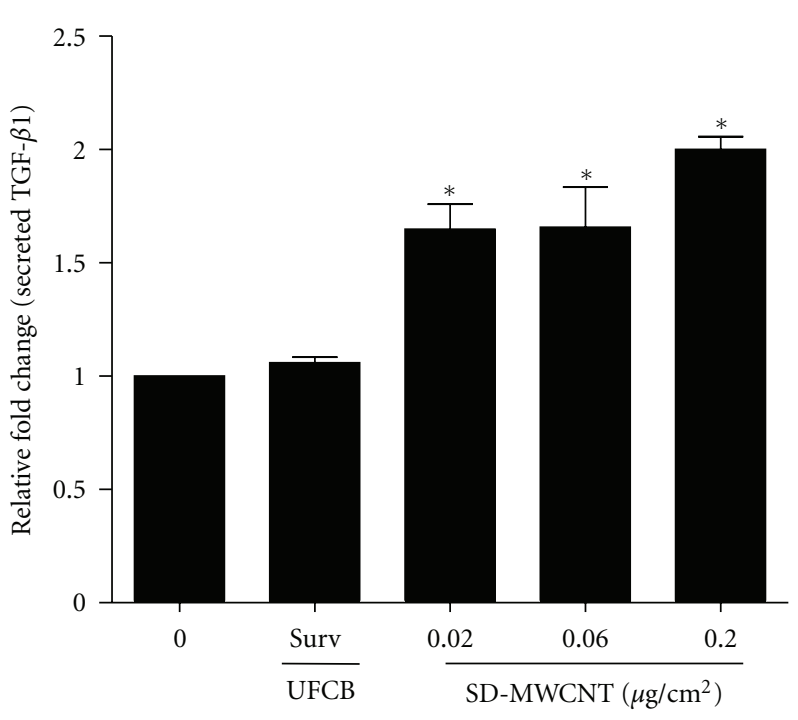

(b)

FIGURE 5: Effect of MWCNT on TGF- $\beta 1$ expression. BEAS-2B cells were exposed to $0.02-0.2 \mu \mathrm{g} / \mathrm{cm}^{2}$ of SD-MWCNT for 48 h. Endogenous TGF- $\beta 1$ levels in cell lysates were measured by Western blotting and compared with nontreated Survanta only control. (a) TGF- $\beta 1$ levels $(45-50 \mathrm{kD})$ were quantified by gel densitometry. (b) Secreted TGF- $\beta 1$ levels in the treated cell supernatants were measured by ELISA. Plots are mean \pm S.D. from 3 independent experiments. ${ }^{*} P<0.05$ versus nontreated control.

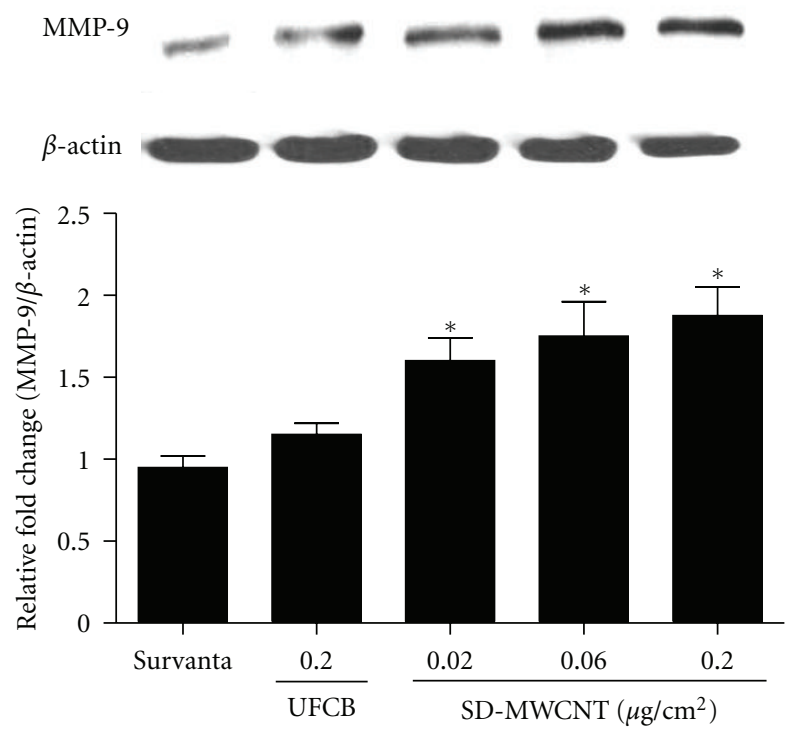

(a)

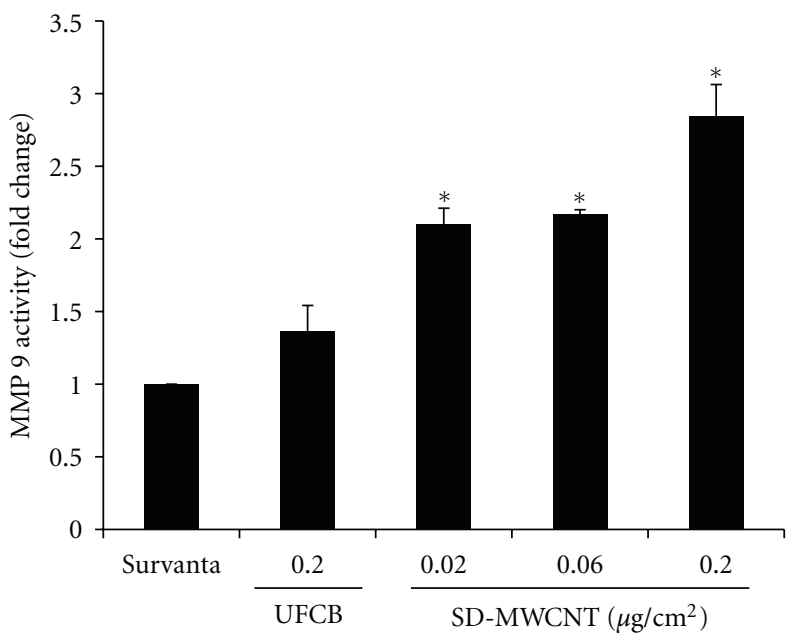

(b)

Figure 6: Effect of MWCNT on MMP-9 expression. BEAS-2B cells were exposed to $0.02-0.2 \mu \mathrm{g} / \mathrm{cm}^{2}$ of SD-MWCNT for $48 \mathrm{~h}$ and the levels of both cellular and secreted MMP-9 were detected. (a) MMP-9 $(92 \mathrm{kD})$ was measured by Western blotting and compared with no treatment (0) and Survanta only controls (Surv). MMP-9 expression levels were quantified by gel densitometry. (b) Secreted MMP-9 in the supernatant of MWCNT-treated BEAS-2B cells detected by ELISA. Plots are mean \pm S.D. from 4 independent experiments $* P<0.05$ versus Survanta only control. 


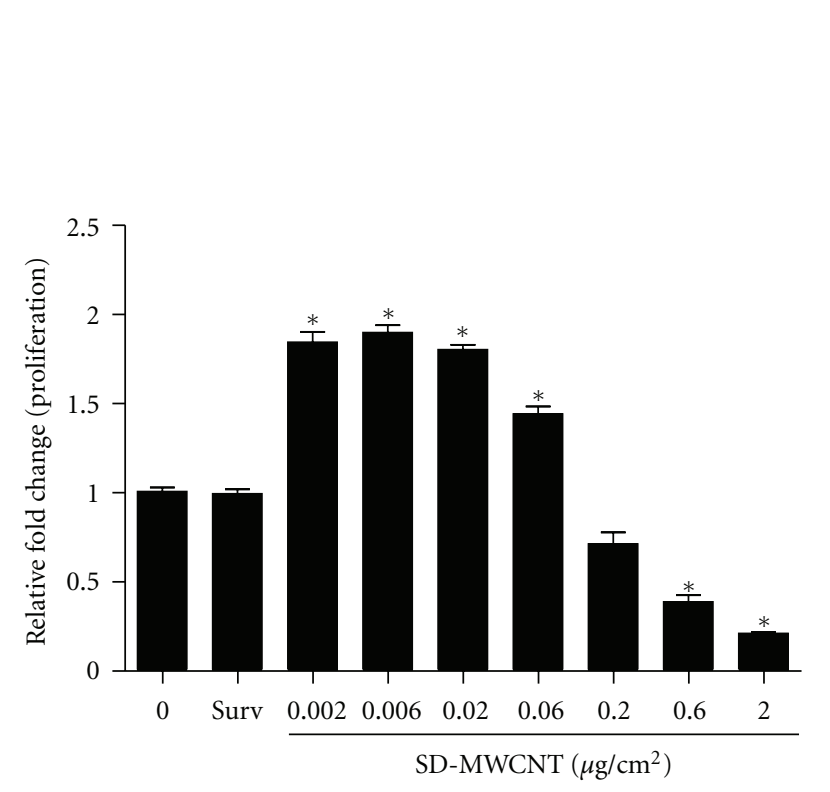

(a)
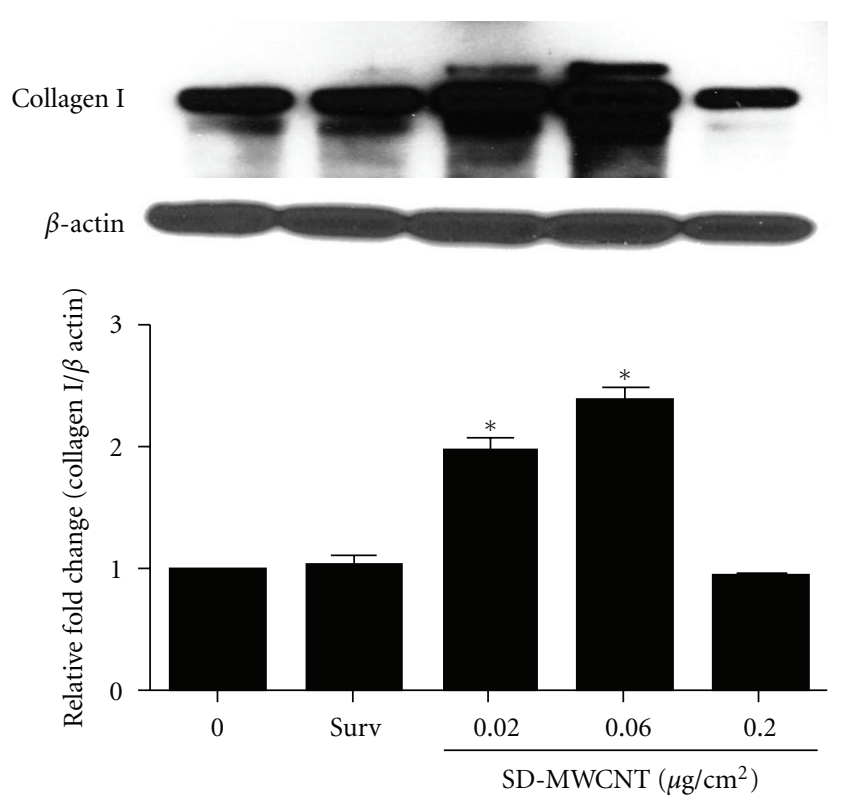

(b)

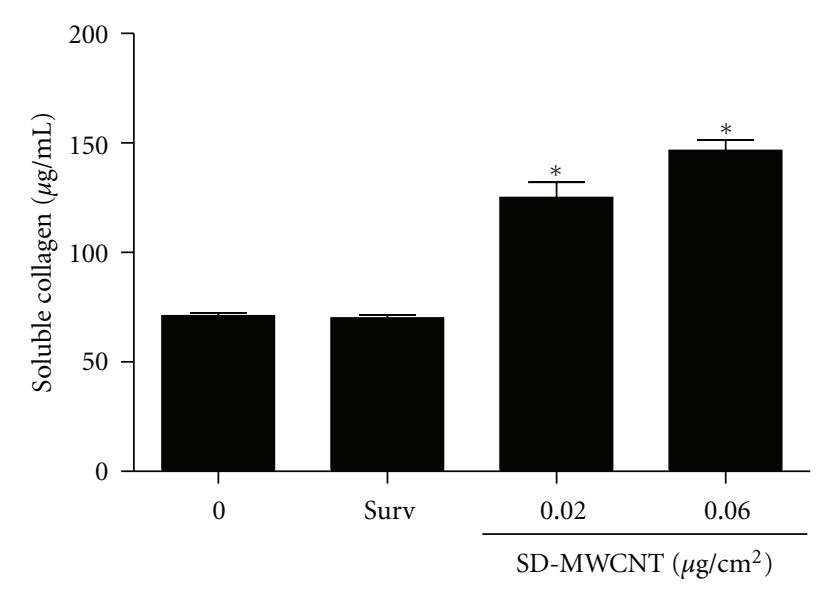

(c)

FIGURE 7: Effects of MWCNT on cell proliferation and collagen expression in human lung fibroblasts. CRL-1490 cells were left untreated (0) or treated with the indicated concentrations of SD-MWCNT or Survanta only (Surv) and analyzed for (a) cell proliferation by WST-1 assay, (b) collagen I expression by Western blotting, and (c) soluble collagen content by Sircol assay. Plots are mean \pm S.D. from 4 independent experiments $* P<0.05$ versus nontreated control.

development will also benefit nanotoxicology research since it is such a simple and easy tool for nanorisk evaluation as compared to the use of animal models which is time consuming, laborious, and impractical for analyzing a wide variety and rapidly increasing number of nanomaterials.

CNT are hydrophobic and tend to form agglomerates in aqueous solutions and biological fluids. In order to mimic physiological condition that inhaled MWCNT will contact alveolar surface which is covered by lung surfactant, a natural lung surfactant, Survanta, was used as a dispersing agent in this study. Survanta as a dispersing agent provides certain advantages; it is biocompatible, commercially available, and easy to prepare with no apparent cytotoxicity when used at the indicated doses [8]. FESEM analysis of Survantadispersed MWCNT showed that Survanta is effective in reducing the MWCNT agglomerate size (Figure 1) which is similar to aerosolized MWCNT. This observation supports the use of Survanta-dispersed MWCNT to mimic airborne workplace exposure since a single MWCNT fiber is a very unlikely existence. Size distribution analysis showed good uniformity of dispersion of the MWCNT (Figure 2). The more potent bioeffect of SD-MWCNT could be due to an increase in the number of particles per unit mass and surface area which increases their interaction with cells as demonstrated in Figure 3.

Cytotoxicity studies of the MWCNT were performed to optimize the doses relevant to in vivo studies [4]. The doses of MWCNT used in this study $\left(0.02-0.6 \mu \mathrm{g} / \mathrm{cm}^{2}\right)$ are derived from in vivo pulmonary exposure doses $(10-80 \mu \mathrm{g} /$ mouse $)$ of MWCNTs that induce lung fibrosis in animals. This 

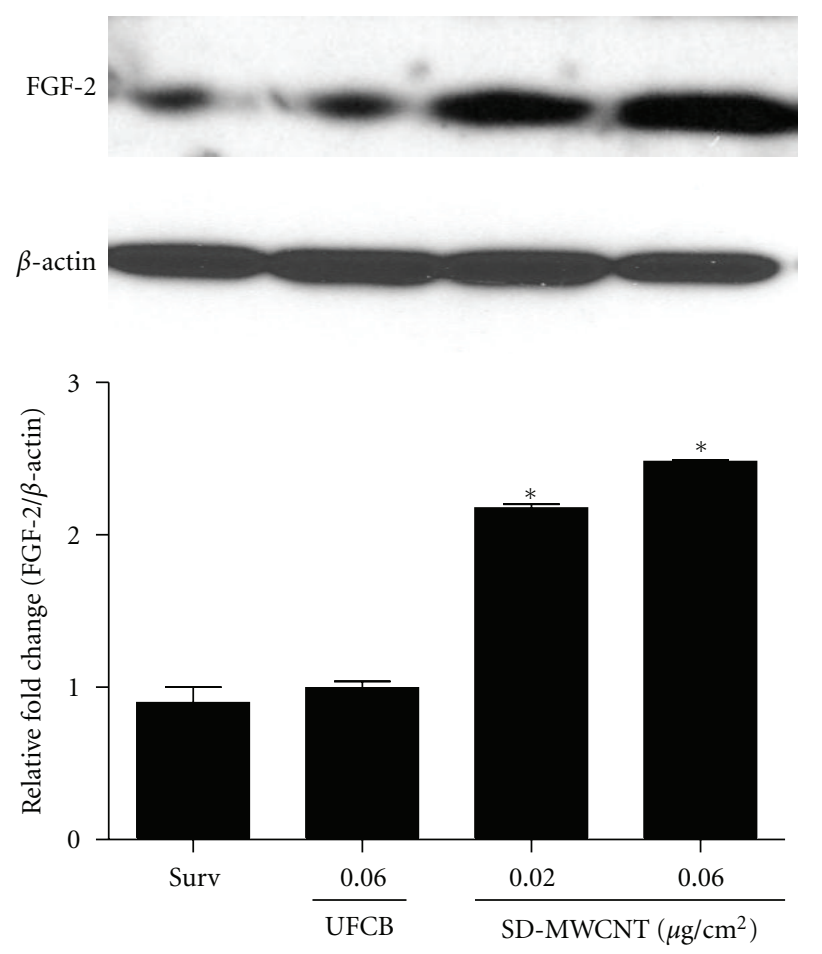

FIGURE 8: Induction of FGF-2 by MWCNT in lung fibroblasts. Fibroblast CRL-1490 cells were exposed to the indicated concentrations of SD-MWCNT or Survanta for $48 \mathrm{~h}$ and analyzed for FGF-2 expression by Western blotting. FGF-2 expression levels were quantified using gel densitometry. Plots are mean \pm S.D. from 4 independent experiments. ${ }^{*} P<0.05$ versus Survanta only control.

dose range of MWCNT was found to significantly induce toxicity in lung epithelial BEAS-2B cells (Figures 4-6). A similar result was also observed in lung epithelial A549 cells, although the response in this cell line was less pronounced than in the BEAS-2B cell line. The results of the cytotoxicity studies also suggest that the dispersed form of MWCNT is more toxic to BEAS-2B cells than the nondispersed form. The variable response of BEAS-2B to ND- and SD-MWCNT exposure observed in the present study was likely due to the difference in agglomerate size or contact surface area with the cells. Although CNT have been reported to cause artifacts in the WST-1 assay $[17,21]$, the doses of MWCNT used in this study were orders of magnitude lower than those reported to adsorb the formazan dye used in this assay. Furthermore, direct cell counting experiments gave similar results. These data are consistent with nanoparticle toxicity studies in nonlung cell lines using other dispersing agents $[22,23]$. The variable response to low-dose ND- and SDMWCNT is likely due to the difference in particle size and contact surface area with the cells.

Fibrosis is a disease of multiple cellular origin involving complex and interrelated signaling pathways. Lung alveolar microphages (AMs) and epithelial cells play an important role in the regulation of fibrosis by producing cytokines and growth factors along with fibroblasts $[10,22,23]$. For example, TGF- $\beta 1$ is one of the most potent fibrogenic mediators $[11,24]$ and is found to be elevated in mouse lungs after pulmonary exposure to CNT $[18,25,26]$. Once secreted from stimulated or injured AM or epithelial cells into the ECM, TGF- $\beta 1$ can stimulate fibroblasts to produce collagen that contributes to epithelial-mesenchymal transition [27]. Unlike microsized particles, well-dispersed CNT might be selectively engulfed by AM which is being investigated in our laboratory. In this study, the bioeffects of MWCNT in epithelial cells and fibroblasts are part of a series of nanotoxicology studies using different individual lung cells. Several well-accepted fibrogenic mediators were first checked. SDMWCNT induced TGF- $\beta 1$ in BEAS- $2 \mathrm{~B}$ cell, as well as an elevated level of secreted TGF- $\beta 1$ in cell culture supernatants of the same MWCNT-treated cells (Figure 5(b)). MMP9 is a key regulator of pulmonary fibrosis and is known to be involved in the pathogenesis of lung fibrosis mainly through its ability to regulate the ECM [12]. An elevated level of MMPs in the ECM is generally indicative of a fibrotic or reparative process. MWCNT upregulated the expression of MMP-9 (Figure 6), suggesting the involvement of this fibrogenic mediator in MWCNT-induced lung fibrosis. This study also suggests that MMP-9 and TGF- $\beta 1$ may serve as potential early biomarkers for CNT-induced fibrosis.

Pulmonary inhaled particles are normally excluded from the interstitial connective tissue by the protective epithelial barrier. However, recent studies have shown that welldispersed CNT can enter the interstitial space $[4,6,27]$. Therefore, interstitial lung fibroblast was specifically chosen for our in vitro studies to determine its direct interaction with the dispersed MWCNT. SD-MWCNT enhanced the proliferation of lung fibroblasts at lower doses $\left(0.002-0.06 \mu \mathrm{g} / \mathrm{cm}^{2}\right)$ but were cytotoxic at doses $>0.6 \mu \mathrm{g} / \mathrm{cm}^{2}$ (Figure $7(\mathrm{a})$ ). The stimulating effect of SD-MWCNT on lung fibroblasts may contribute to rapid interstitial fibrosis induced by dispersed MWCNT. SD-MWCNT also stimulated collagen I expression in cultured lung fibroblasts (Figure 7(b)) and secreted soluble collagen from the cells (Figure $7(\mathrm{c})$ ) as compared to controls. This finding is in good agreement with a recent in vivo study showing a dose- and time-dependent effect of SD-MWCNT exposure on lung collagen content in mice [7]. Figure 7(b) also showed that MWCNT-induced collagen I expression was reduced at the concentration of $0.2 \mu \mathrm{g} / \mathrm{cm}^{2}$, which is likely due to a decrease in fibroblast cell viability (Figure $7(\mathrm{a})$ ). The aforementioned data suggest that direct stimulation of both fibroblast cell proliferation and collagen production may be an explanation for the unusual rapid interstitial fibrosis induced by dispersed MWCNT. Collagen, a hallmark of fibrosis, could serve as a biomarker for fibrogenicity testing of nanomaterials using this cultured fibroblast model. Our study also showed that MWCNT induced FGF-2 (Figure 8), which is known to stimulate fibroblast cell growth. The precise role of this and other growth factors and cytokines in MWCNT-induced lung fibrosis are unclear and are being investigated in our laboratory.

Currently, there is a great need for the development of rapid and reliable methods for toxicity and fibrogenicity testing of nanomaterials due to their growing applications and incorporation into commercial products at a time when there 
is a limited understanding of their possible health effects. Traditional fibrosis studies in animals, while providing useful information about the fibrogenicity of nanomaterials, are time consuming, laborious, and impractical for analysis of the vast variety and rapidly increasing number of nanomaterials. The present study describes an alternative in vitro method for fibrogenicity testing of nanomaterials based on the use of relevant human lung cell models. The ability of CNT to induce fibrogenic factors in lung cells and stimulate fibroblast cell growth and collagen production was used as indicators of lung fibrogenesis. Consistent with previous in vivo data by our group and others, the results of this study demonstrated the potential usefulness of the in vitro cell models as rapid screening tools for fibrogenicity testing of other nanomaterials. The cell models may also be used to aid detailed mechanistic investigations of the fibrogenic process.

In conclusion, the results of this study indicate that Survanta was effective in dispersing MWCNT agglomerates in suspension into nanosized structures which are similar in size as their aerosolized form. MWCNT exhibited a dosedependent cellular effect on human lung epithelial cells which is more pronounced in a dispersed form as compared to nondispersed form. SD-MWCNT significantly elevated the levels of fibrogenic mediators such as TGF- $\beta 1$ and MMP9 , and stimulated fibroblast proliferation and upregulated its expression of collagen I and secretion of FGF-2. This study describes an alternative in vitro method for fibrogenicity testing of MWCNT which could be useful in mechanistic investigations of lung fibrosis induced by CNT and other nanomaterials.

\section{Disclaimer}

The findings and conclusions in this report are those of the authors and do not necessarily represent the views of the National Institute for Occupational Safety and Health.

\section{Acknowledgments}

This work was supported by Grants of NORA (FY09 LMW6), NIH (HL-095579), and NSF (EPS-1003907).

\section{References}

[1] C. A. Poland, R. Duffin, I. Kinloch et al., "Carbon nanotubes introduced into the abdominal cavity of mice show asbestoslike pathogenicity in a pilot study," Nature Nanotechnology, vol. 3, no. 7, pp. 423-428, 2008.

[2] H. J. Johnston, G. R. Hutchison, F. M. Christensen et al., "A critical review of the biological mechanisms underlying the in vivo and in vitro toxicity of carbon nanotubes: the contribution of physico-chemical characteristics," Nanotoxicology, vol. 4, no. 2, pp. 207-246, 2010.

[3] K. Donaldson, F. A. Murphy, R. Duffin, and C. A. Poland, "Asbestos, carbon nanotubes and the pleural mesothelium: a review of the hypothesis regarding the role of long fibre retention in the parietal pleura, inflammation and mesothelioma," Particle and Fibre Toxicology, vol. 7, no. 1, article 5, 2010.

[4] D. W. Porter, A. F. Hubbs, R. R. Mercer et al., "Mouse pulmonary dose- and time course-responses induced by exposure to multi-walled carbon nanotubes," Toxicology, vol. 269, no. 2-3, pp. 136-147, 2010.

[5] R. R. Mercer, A. F. Hubbs, J. F. Scabilloni et al., "Pulmonary fibrotic response to aspiration of multi-walled carbon nanotubes," Particle and Fibre Toxicology, vol. 8, no. 1, article 21, 2011.

[6] R. R. Mercer, J. Scabilloni, L. Wang et al., "Alteration of deposition pattern and pulmonary response as a result of improved dispersion of aspirated single-walled carbon nanotubes in a mouse model," American Journal of Physiology, vol. 294, no. 1, pp. L87-L97, 2008.

[7] L. Wang, R. R. Mercer, Y. Rojanasakul et al., "Direct fibrogenic effects of dispersed single-walled carbon nanotubes on human lung fibroblasts," Journal of Toxicology and Environmental Health Part A, vol. 73, no. 5-6, pp. 410-422, 2010.

[8] L. Wang, V. Castranova, A. Mishra et al., "Dispersion of singlewalled carbon nanotubes by a natural lung surfactant for pulmonary in vitro and in vivo toxicity studies," Particle and Fibre Toxicology, vol. 7, no. 1, article 31, 2010.

[9] M. S. Wilson and T. A. Wynn, "Pulmonary fibrosis: pathogenesis, etiology and regulation," Mucosal Immunology, vol. 2, no. 2, pp. 103-121, 2009.

[10] C. Agostini and C. Gurrieri, "Chemokine/cytokine cocktail in idiopathic pulmonary fibrosis," Proceedings of the American Thoracic Society, vol. 3, no. 4, pp. 357-363, 2006.

[11] B. C. Willis and Z. Borok, "TGF- $\beta$-induced EMT: mechanisms and implications for fibrotic lung disease," American Journal of Physiology, vol. 293, no. 3, pp. L525-L534, 2007.

[12] S. Chakrabarti and K. D. Patel, "Matrix metalloproteinase-2 (MMP-2) and MMP-9 in pulmonary pathology," Experimental Lung Research, vol. 31, no. 6, pp. 599-621, 2005.

[13] C. Yan and D. D. Boyd, "Regulation of matrix metalloproteinase expression expression," Journal of Cellular Physiology, vol. 211, no. 1, pp. 19-26, 2007.

[14] K. J. Greenlee, Z. Werb, and F. Kheradmand, "Matrix metalloproteinases in lung: multiple, multifarious, and multifaceted," Physiological Reviews, vol. 87, no. 1, pp. 69-98, 2007.

[15] M. M. Gueders, J. M. Foidart, A. Noel, and D. D. Cataldo, "Matrix metalloproteinases (MMPs) and tissue inhibitors of MMPs in the respiratory tract: potential implications in asthma and other lung diseases," European Journal of Pharmacology, vol. 533, no. 1-3, pp. 133-144, 2006.

[16] J. J. Atkinson and R. M. Senior, "Matrix metalloproteinase-9 in lung remodeling," American Journal of Respiratory Cell and Molecular Biology, vol. 28, no. 1, pp. 12-24, 2003.

[17] N. Khalil, Y. D. Xu, R. O’Connor, and V. Duronio, "Proliferation of pulmonary interstitial fibroblasts is mediated by transforming growth factor- $\beta 1$-induced release of extracellular fibroblast growth factor-2 and phosphorylation of p38 MAPK and JNK," The Journal of Biological Chemistry, vol. 280, no. 52, pp. 43000-43009, 2005.

[18] A. A. Shvedova, E. R. Kisin, R. Mercer et al., "Unusual inflammatory and fibrogenic pulmonary responses to singlewalled carbon nanotubes in mice," American Journal of Physiology, vol. 289, no. 5, pp. L698-L708, 2005.

[19] M. Wolforth et al., "Acute pulmonary responses to MWCNT inhalation," The Toxicologist, vol. 120, article A53, 2011.

[20] N. A. Monteiro-Riviere, A. O. Inman, and L. W. Zhang, "Limitations and relative utility of screening assays to assess engineered nanoparticle toxicity in a human cell line," Toxicology and Applied Pharmacology, vol. 234, no. 2, pp. 222-235, 2009. 
[21] J. M. Worle-Knirsch, K. Pulskamp, and H. F. Krug, "Oops they did it again! carbon nanotubes hoax scientists in viability assays," Nano Letters, vol. 6, no. 6, pp. 1261-1268, 2006.

[22] T. A. Wynn and L. Barron, "Macrophages: master regulators of inflammation and fibrosis," Seminars in Liver Disease, vol. 30, no. 3, pp. 245-257, 2010.

[23] M. Guarino, A. Tosoni, and M. Nebuloni, "Direct contribution of epithelium to organ fibrosis: epithelial-mesenchymal transition," Human Pathology, vol. 40, no. 10, pp. 1365-1376, 2009.

[24] D. Sheppard, "Transforming growth factor $\beta$ : a central modulator of pulmonary and airway inflammation and fibrosis," Proceedings of the American Thoracic Society, vol. 3, no. 5, pp. 413-417, 2006.

[25] C. Ronzani, C. Spiegelhalter, J. L. Vonesch, L. Lebeau, and F. Pons, "Lung deposition and toxicological responses evoked by multi-walled carbon nanotubes dispersed in a synthetic lung surfactant in the mouse," Archives of Toxicology, vol. 86, no. 1 , pp. 137-149, 2012.

[26] A. A. Shvedova, E. Kisin, A. R. Murray et al., "Inhalation vs. aspiration of single-walled carbon nanotubes in C57BL/6 mice: inflammation, fibrosis, oxidative stress, and mutagenesis," American Journal of Physiology, vol. 295, no. 4, pp. L552L565, 2008.

[27] S. G. Han, R. Andrews, and C. G. Gairola, "Acute pulmonary response of mice to multi-wall carbon nanotubes," Inhalation Toxicology, vol. 22, no. 4, pp. 340-347, 2010. 

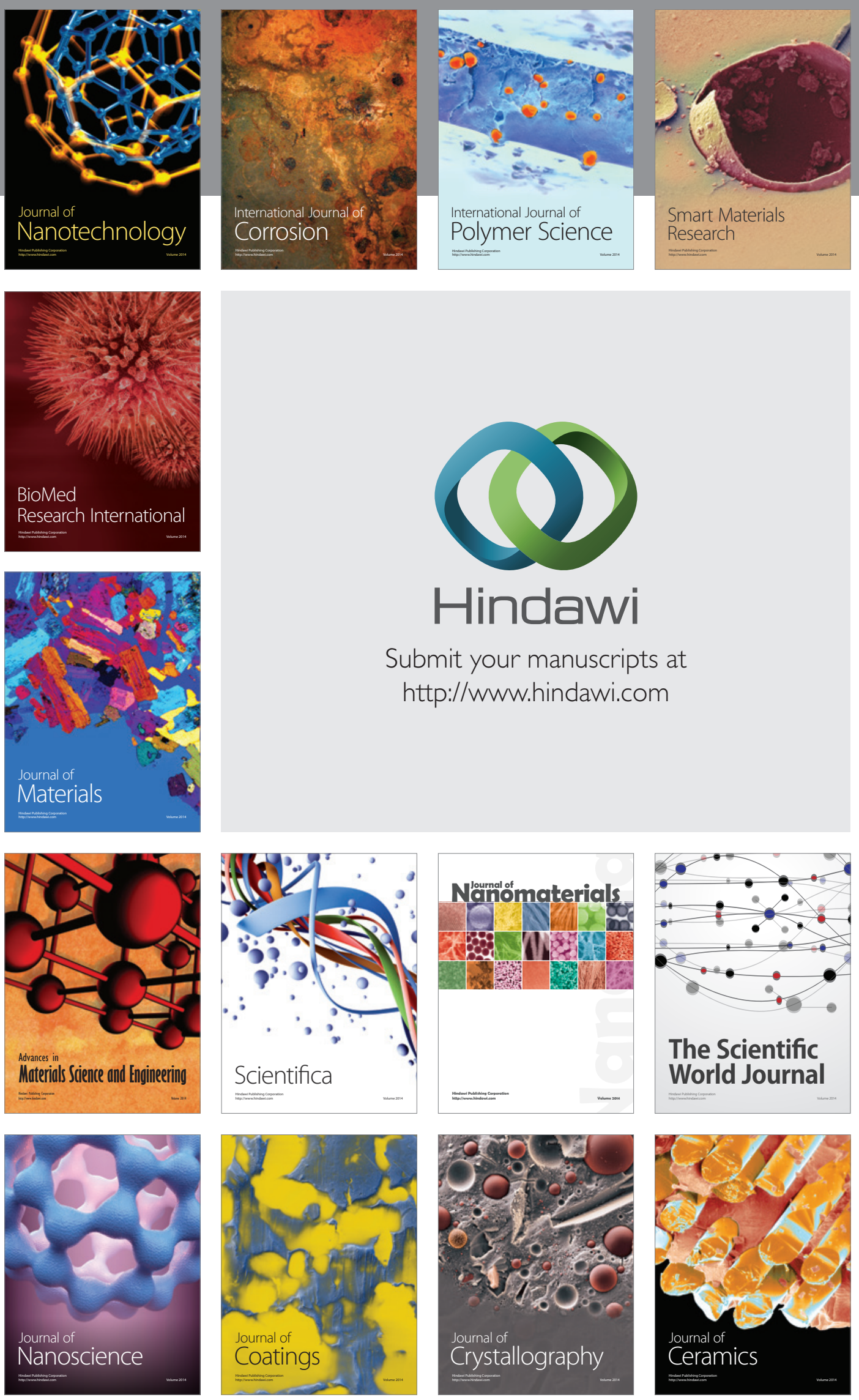

The Scientific World Journal

Submit your manuscripts at

http://www.hindawi.com

\section{World Journal}

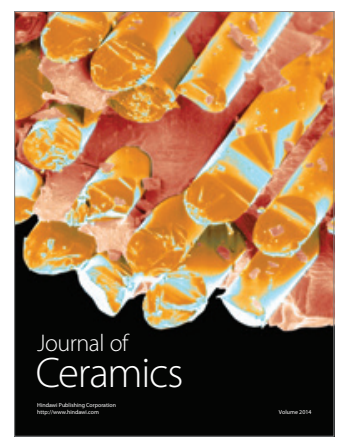

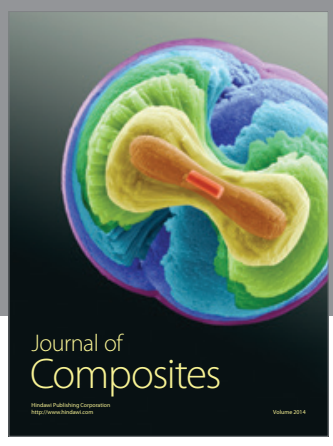
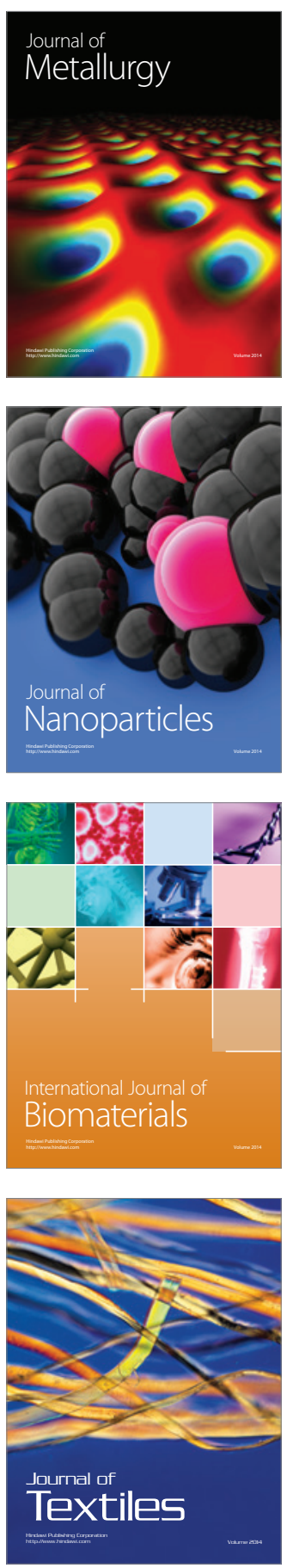